\title{
PERICARDITIS AND CARDIAC TAMPONADE IN A MALE PATIENT WITH JUVENILE SYSTEMIC LUPUS ERYTHEMATOSUS: CASE REPORT
}

Angélica Maria Assunção da Ponte Lopes ${ }^{1, \star}$, Roberta Oriana Assunção Sousa da Ponte Lopes ${ }^{2}$, Aritana Costa Araújo ${ }^{1}$, Natalya Laryssa Silva Sousa ${ }^{1}$, Luana Moura Luz Fé ${ }^{1}$, Fernanda Cristina Costa Silva ${ }^{1}$, Clara D’Maria Lopes Rapouso Sousa e Sousa ${ }^{1}$

1.Centro Universitário UniFacid Wyden, Teresina (PI), Brazil. 2.Hospital Infantil Lucídio Portela, Teresina (PI), Brazil.

*Corresponding author: angelica.mariaapl@gmail.com

\section{BACKGROUND}

Juvenile systemic lupus erythematosus (JSLE) is a chronic inflammatory pathology, which is more prevalent in females (9:1). This condition is influenced by genetic, immunological and environmental factors.

\section{CASE REPORT}

Male, 14 years old, 4 months ago, with arthritis in the wrists and ankles. He evolved with eyelid edema, syncope, hypotension and precordial pain. Tachydyspneic, acyanotic, afebrile. Cardiac auscultation: regular rhythm in two stages, hypophonic sounds, without murmur and with pericardial friction. Tests: Hb 12, Ht 37\%, leukocytes 3,000, lymphopenia, platelets 251,000, PCR 12 , ESR 34, FAN reagent 1: 2500, C3: 129, C4: 23,4, anti-DNA negative, anti-SM:<5, anti-SSA/Ro: <7, anti-SSB/La: <7, anticoagulant lupus: negative, 24-hour proteinuria: $4.5 \mathrm{mg} / 24 \mathrm{~h}$. Doppler echocardiography: moderate pericardial effusion with slight collapse of the right ventricle. He underwent pulse therapy with methylprednisolone and prednisone. Currently using prednisone, hydroxychloroquine and azathioprine.

\section{CONCLUSION}

Cardiac involvement in JSLE is present in up to $25 \%$ of patients, with pericarditis being the most frequent form. This impairment has significant morbidity and mortality and is clinically manifested in only a quarter of patients, and may progress in $6 \%$ of cases with cardiac tamponade. The diagnosis and institution of early treatment are crucial for a better prognosis. 